\title{
O JOGRAL ATREVIDO - A atuação dos poetas de baixo extrato social no trovadorismo medieval ibérico (séculos XIII e XIV)
}

José D'Assunção Barros ${ }^{a}$

\begin{abstract}
Resumo
O objeto deste artigo é discutir as tensões sociais nas sociedades medievais ibéricas dos séculos XIII e XIV, examinando mais especificamente a poesia e práticas trovadorescas do periodo através das cantigas dos jograis que se destacaram no trovadorismo das cortes de Portugal e Castela na segunda metade do século XIII. Trata-se de examinar como os poetas de baixa extração social, oriundos de camadas diversas da população, adentram um espaço também frequentado pela nobreza e pelo próprio Rei, particularmente no espaço social e cultural do Paço.
\end{abstract}

Palavras chaves: Trovadores medievais ibéricos; tensões sociais, jograis. 
1 A poesia deste circuito trovadoresco está registrada em alguns cancioneiros. O Cancioneiro da Ajuda teria sido compilado na corte de Afonso X de Castela, na segunda metade do século XIII. Na primeira metade do século XIV teria sido compilado um Livro de Cantigas do Conde Dom Pedro, que, embora desaparecendo posteriormente, teria dado origem ao Cancioneiro da Vaticana e ao Cancioneiro da Biblioteca Nacional, dois cancioneiros compilados na Itália já no século XVI. Estes dois cancioneiros, somados ao Cancioneiro da Ajuda, constituem grandes coletâneas da poesia trovadoresca ibérica que, à sua época, circulava nas cortes régias de Portugal e Castela. Os manuscritos encontram-se atualmente nas bibliotecas que lhes emprestam seus nomes: Biblioteca da Ajuda (CA), Biblioteca da Vaticana (CV), Biblioteca Nacional (CBN). Os três cancioneiros conhecidos, encontram-se atualmente impressos.
A Idade Média conheceu diversos movimentos trovadorescos de bastante interesse tanto para a História da Poesia Ocidental como para a própria História Social. Do movimento dos trouvéres no sul da França - berço do Amor Cortês - ao movimento dos Minnesingers na região da atual Alemanha, esses movimentos poético-musicais abarcavam poetas-cantores de todas as categorias sociais, ocorrendo inclusive o registro de reis trovadores - como foi o caso de Ricardo Coração de Leão na Inglaterra, de Afonso X de Castela e de Dom Dinis em Portugal. Bastante singular, e prosperando entre os séculos XIII e XIV, foi o movimento dos trovadores galego-portugueses - assim chamado porque, embora abarcando os reinos de Portugal, Galiza, Leão e Castela, os poetas-cantores deste circuito trovadoresco utilizavam como idioma comum o galego-português. ${ }^{1}$

Uma das singularidades do trovadorismo galego-português - o que o situa em algum nível de contraste em relação a outros trovadorismos da Europa Medieval - era a excepcional liberalidade concedida aos trovadores de diversos níveis sociais com relação ao livre encaminhamento de críticas sociais, políticas e pessoais através da poesia satírica. Há célebres registros de críticas ao próprio rei, para o caso de Afonso X de Castela, ele mesmo um dos trovadores que em meados do século XIII apresentavam-se como produtores poéticos no paço trovadoresco. De igual maneira, trovadores de todas as categorias sociais enfrentavam-se através do verso em cantigas de escárnio e em tenções. Nosso objetivo neste artigo será examinar, na lírica trovadoresca galego-portuguesa, as críticas dos trovadores de menor categoria social, que não raro duelavam com bastante atrevimento contra trovadores-fidalgos que estariam muito acima deles na escala social prevista pela hierarquia medieval ibérica.

A última ponta do vasto espectro trovadoresco, que, entre os poetas galego-portugueses, abarcava os mais diversos tipos sociais, era precisamente aquele jogral de nível "peão" ou "assoldadado" - ele que, fora do universo artístico dos trovadores, pouco seria, mas que aqui, nos paços trovadorescos de Portugal e Castela, aparece audaciosamente enfrentando os nobres e cavaleiros vilãos a partir da disputatio lírica. Por vezes, aliás, é como acompanhante de um trovador ou segrel de maior status social que o jogral adentra a corte. Mas então, pelo menos em 
alguns casos, esse mesmo jogral começa a compor. E, logo, a reivindicar também para si o status de trovador.

As cantigas que ficaram registradas nos cancioneiros da época mostram-nos que, dentro da pluralidade trovadoresca, o jogral recebe um expressivo quinhão de liberdade, mas também os seus limites e a resistência dos trovadores que representam segmentos sociais superiores, nobres ou não. Com efeito, no circuito trovadoresco galego-português, alguns jograis de condição inferior são singularmente "atrevidos", prontos a desafiar os trovadores de mais alta estirpe. Além disso, sua projeção social através da arte trovadoresca torna-se uma possibilidade muito concreta. E, por isto mesmo, as resistências a esta projeção e a esta liberdade jogralesa foram muito bem explicitadas liricamente. Uma força gera sempre as reações correspondentes, repetindo-se aqui o que também poderia ser notado a respeito do cavaleiro vilão que adentra o Paço e que começa a enfrentar as resistências dos trovadores-fidalgos da nobreza tradicional.

É preciso destacar também que esse adentrar do "popular" na corte, agora representado pela figura do jogral inferior, era certamente parte do projeto trovadoresco régio. No contexto de um acirrado processo de centralização monárquica, no qual o rei em diversas ocasiões deveria enfrentar as resistências da nobreza do reino, ter os jograis circulando insolentemente no meio da nobreza mais afidalgada correspondia ao jogo de tensões pretendido pelo monarca. Além do mais, este jogral inserido na corte podia em certos casos incorporar a voz do rei, tal como ocorre, por exemplo, na CV 1124, em que o jogral Diego Pezelho entra na constelação de escárnios desfechados contra os nobres traidores de Dom Sancho II no episódio da sua deposição como rei de Portugal. Neste ponto, portanto, este jogral específico atua a favor do monarca de seu paço trovadoresco (Afonso X, que se colocara a favor do rei deposto). Com especial ironia, o jogral ironiza tanto as autoridades eclesiásticas como os alcaides traidores, que estiveram juntos a favor de D. Afonso III:

Meu senhor arcebispo, and' eu escomungado, por que fiz lealdade: enganou-mi o pecado.

Soltade-m' ai, senhor,

e jurarei, mandado, que seja traedor.

(Diego Pezelho, jograr; CBN 1592, CV 1124, la estrofe) ${ }^{2}$ 
Imaginando um nobre que, no conflito, tivesse permanecido fiel a seus vínculos de vassalidade - isto é, não traindo o rei D. Sancho II na entrega de castelos a seu adversário - o autor coloca na voz de seu cavaleiro imaginário um discurso irônico em que pede perdão por não ter sido traidor. Trata-se do tradicional discurso a favor do modelo impecável de cavalaria, com o qual se pretende investir contra todos os nobres que o transgrediram. Portanto, atuando em consonância aos desígnios de seu monarca protetor, o jogral Diego Pezelho se apropria do imaginário da nobreza para voltá-lo contra uma parte dela mesma. Exemplo perfeito de como um jogral empresta sua voz a muitas outras vozes.

O jogral podia falar, entrementes, em seu próprio interesse, expressando liricamente sua posição de classe e suas ambições de ascender socialmente dentro da corte trovadoresca. Quando "tençoava" contra trovadores de alta estirpe, aliás, podia estar alinhado com outros trovadores de alta estirpe que fossem rivais dos primeiros, e que, possivelmente, se divertiam com as impertinências do jogral contra seus desafetos. Contudo era também possível que o jogral desagradasse a nobreza como um todo, questionando o seu status quo ou entrando sub-repticiamente na querela que sugeria que haveria uma "nobreza do talento", muito acima da "nobreza de sangue" proposta pelas hierarquias medievais. As reações vinham então em verdadeiros blocos de escárnios demarcatórios, depreciando francamente a atividade do "jogral atrevido".

O exemplo mais notável de "jogral atrevido" é o famoso Lourenço - trovador do tempo de Afonso X e Afonso III que atuou a princípio em Portugal, e depois em Castela. Nas duas cortes esmerou-se em "tençoar" contra outros trovadores, não importando de que nível social fossem. Por isso, atraiu contra si resistências dos mais diversos trovadores. Ao que parece, Lourenço teria ultrapassado aqueles limites da liberdade consentida a um poeta-cantor da condição social inferior, pelo

2 As abreviaturas CA, CV e CBN serão utilizadas, respectivamente, como referências aos três cancioneiros (Cancioneiro da Ajuda, Cancioneiro da Vaticana, Cancioneiro da Biblioteca Nacional). menos em Portugal. Limites que não eram claros, mas que a partir de certo ponto começaram a se manifestar em uma hostilização generalizada que possivelmente o obrigou a mudar-se para Castela. Ali parece ter tido mais sucesso, já que conquista uma certa autonomia profissional e até algum sucesso material, conforme nos indica uma cantiga em que o fidalgo Pero Gomes 
Barroso deprecia algumas casas que Lourenço havia comprado ("Pero Lourenço comprastes / uas casas, e mercastes / delas mal"; CV 1051). Mas antes de atingir este ponto, Lourenço havia adentrado o paço trovadoresco pelo mesmo caminho que muitos outros jograis: trabalhando a serviço de outrem. Seu mais notório patrão foi o já mencionado João Garcia de Guilhade. A relação profissional é documentada pela CV 1105, já citada, na qual o jogral queixa-se da impontualidade de seu patrão-trovador em lhe pagar o salário devido.

Devido à proximidade, as primeiras tenções de Lourenço foram precisamente contra o cavaleiro vilão. Algumas eram ensaiadas, e destinavam-se a motejar outros trovadores. Mas diversas delas exprimem efetivamente as tensões entre dois representantes de segmentos sociais que se antagonizam. É aí que o cavaleiro vilão João Garcia de Guilhade procura demarcar um lugar social que pretende para o "peão" Lourenço. Quer interditar-lhe a categoria "trovador" exatamente da mesma forma como os trovadores-fidalgos a interditavam a ele mesmo. Como se dissesse: "o compartimento 'trovador' só vai até mim. Daqui para lá, são todos jograis".

O confronto toma forma a partir do momento em que Lourenço reivindica para si a função de compositor, adquire mais autonomia e se autopromove a "trovador". João Garcia de Guilhade lhe dirige então dois escárnios (CVs 1106 e 1107), nos quais adota a já conhecida estratégia de depreciar o jogral como "compositor", e até na função de mero acompanhante. No primeiro deles, saúda sarcasticamente a autopromoção de Lourenço a trovador:

Lourenço, pois te quitas de rascar e desemparas o teu citolon, rogo-te que nunca digas meu son e já mais nunca mi farás pesar; ca, per trobar, queres já guarecer, e farás-m' ora desejos perder do trobador que trobou do Juncal.

Ora cuido eu cobrar o dormir que perdi: sempre, cada que te vi rascar no cep' e tanger, non dormi; 
mais, poi-lo queres já de ti partir,

pois guarecer [buscas] per trobar,

Lourenço, nunca irás a logar

$\mathrm{u}$ tu non faças as gentes riir.

E vês, Lourenço, se Deus mi pardon,

pois que me tolhes do cepo pavor

e de cantar, farei-t' eu sempr' amor,

e tenho que farei mui gran razon;

e direi-t' i qual amor $\mathrm{t}^{\prime}$ eu farei:

já mais nunca teu cantar oirei,

que non riia mui de coraçon;

Ca vês, Lourenço, muito mal prendi

de teu rascar e do cep' e de ti;

mais, pois $\mathrm{t}^{\prime}$ en quitas, $\mathrm{cu}[\mathrm{i}] \mathrm{do}$ ti perdon.

(Joan Garcia de Guilhade; CBN 1495, CV 1106)

O argumento é que, com a autopromoção de Lourenço a trovador, Guilhade já poderia descansar sossegado - já que nunca mais teria de ouvir o jogral junto a si, cantando e tocando mal o seu citolão. "Rascar" (rasgar) o citolão é, logo no primeiro verso, o depreciativo com que Guilhade tenta rebaixar o talento musical de Lourenço. Da mesma forma "cepo" (v. 9), que é um nome pejorativo que se dava ao instrumento de cordas. Também é citado no verso 9 um certo "trobador que trobou do Juncal". Ao que tudo indica, seria um trovador sabidamente ridículo e irrisório. Guilhade declara que, contudo, Lourenço o superava muito em mal versejar.

Registra também a pretensão de Lourenço de deixar de ser um mero jogral acompanhante para se tornar compositor de suas próprias cantigas ("mais, poi-lo queres já de ti partir, / pois guarecer [buscas] per trobar", v. 11-12). Quanto a isto, aliás, Guilhade declara na cantiga seguinte (CV 1107) que o melhor para Lourenço seria deixar de ser jogral e trovador, isto é, tanto acompanhante como compositor. O mesmo argumento é apresentado na primeira estrofe de uma tenção entre os dois, onde Guilhade principia por declarar absurdas as pretensões de Lourenço em se tornar trovador, já que sequer bom jogral acompanhante ele era: 
- Lourenço, jograr, ás mui gran sabor

de citolares, ar queres cantar,

des i ar filhas-te $\log ^{\prime}$ a trobar

e tees-t' ora já por trobador;

e por tod' esto ua ren ti direi:

Deus me confonda, se oj' eu i sei

destes mesteres qual fazes melhor.

- Joan Garcia, soo sabedor

de meus mesteres sempr' adeantar,

e vós andades por mi os desloar;

pero, non sodes tan desloador

que, con verdade, possades dizer

que meus mesteres non sei ben fazer;

mais vós non sodes i conhocedor.

- Lourenço, vejo-t' agora queixar

pola verdade que quero dizer:

metes-me já por de mal conhocer,

mais en non quero tigo pelejar

e teus mesteres conhocer-tos-ei,

e dos mesteres verdade direi:

'ess' é que foi con os lobos arar!'

- Joan Garcia, no vosso trobar

acharedes muito que correger;

e leixade mi, que sei ben fazer

estes mesteres que fui começar;

ca no vosso trobar sei-m' eu com' é:

i á de correger, per bõa fé,

mais que nos meus, en que $\mathrm{m}^{\prime}$ ides travar.

- Ve[e]s, Lourenço, ora $\mathrm{m}^{\prime}$ assanharei, pois mal i entenças, e $t^{\prime}$ ende farei

o citolon na cabeça quebrar.

- Joan Garcia, se Deus mi perdon, mui gran verdade digu' eu na tençon, e vós fazed' o que vos semelhar (Joan de Guilhade e Lourenço, jograr; CBN 1493) 
De saída, a intenção demarcatória expressa-se já no vocativo inicial ("Lourenço, jograr"). Ou seja, o cavaleiro vilão cuida de adjetivar seu oponente à maneira do que comumente faziam os trovadores-fidalgos, que costumavam apor no final das cantigas o designante "jograr" para os trovadores de menor categoria. Isto ou um apelido, dava no mesmo. Demarcar pelo próprio nome. Além disto, "jogral" ou "trovador" (agora utilizando a palavra no sentido de compositor), Guilhade afirma não saber em qual dos dois "mesteres" Lourenço é pior (v. 6-7).

A réplica de Lourenço é imediata. Na segunda estrofe desconhece a competência de Guilhade para julgar seu trabalho poético ("mais vós non sodes i conhocedor", v. 14). Na quarta, afirma que em suas próprias trovas Guilhade encontraria muito o que corrigir (v. 22-23). E declara que, nesse sentido, seus próprios versos são muito superiores aos do cavaleiro vilão ("ca no vosso trobar sei-m' eu com' é: / i á de correger, per bõa fé, / mais que nos meus, en que m' ides travar").

Guilhade encerra a sua parte na tenção ameaçando quebrar o citolão na cabeça do jogral. O que, em todo o caso, não deve ser levado muito a sério, já que eram comuns estas brincadeiras no meio trovadoresco. O mesmo tipo de argumentação, procurando depreciar a qualidade de suas cantigas, Lourenço teve de enfrentar dos trovadores-fidalgos - muito preocupados com o talentoso e atrevido jogral que se projetava no seu espaço de prestígio social. Em uma tenção contra o fidalgo João Peres de Aboin (CV 1010), recebe o mesmo tipo de desafio:

- Lourenço, soias tu guarecer

como podias, per teu citolon,

ou ben ou mal, non ti digu' eu de non,

e vejo-te de trobar trameter;

e quero-t' eu desto desenganar:

ben tanto sabes tu que é trobar

ben quanto sab' o asno de leer

À insinuação de que "sabe tanto de trovar quanto um asno de ler", Lourenço replica assumindo uma verdadeira posição de "bellator lírico". Lembra a seu contendor que já venceu em tenções como aquela vários outros trovadores-fidalgos, que partiram da mesma insinuação. E agora, conforme declara, pretende derrubar o famoso mordomo de D. Afonso III: 
- Joan d' Avoin, já me cometer

veeron muitos por esta razon

que mi dizian, se Deus mi perdon,

que non sabia $\mathrm{n}$ trobar entender;

e veeron poren comigu' entençar,

e figi-os eu vençudos ficar,

e cuido-vos deste preito vencer

A tenção assume aqui toda a sua forma de duelo, de combate lírico no qual um trovador assume-se como oponente do outro. $\mathrm{O}$ verso seguinte é tipicamente demarcatório. Aboin reafirma seu propósito de "desenganar" ao jogral Lourenço quanto a seu propósito de seguir sendo trovador:

- Lourenço, serias mui sabedor,

se me vencesses de trobar nen $\mathrm{d}^{\prime}$ al,

ca ben sei eu quen troba ben ou mal,

que non sabe mais nen um trobador;

e por aquesto te desenganei;

e vês, Lourenço, onde cho direi:

quita-te sempre do que teu non for.

Demarcação por uma dupla via. Por um lado, enaltece a si mesmo e à sua condição de trovador. Só ele, como trovador (isto é, trovador-fidalgo) seria ali capaz de prejulgar quem trova bem ou quem trova mal. E mais, de outro lado a interdição explícita: o espaço composicional-trovadoresco é naturalmente estranho a um jogral de condição inferior ("quita-te sempre do que teu non for").

Depois do que, Lourenço encerra sua participação afirmando que, de forma nenhuma, abandonará o trovar. Primeiro porque tem plena consciência de seus méritos. Depois, porque encontra na sua atividade uma grande fonte de prazer e satisfação:

Joan d' Avoin, por Nostro Senhor,

por que leixarei eu trobar atal

que mui ben faç' e que muito mi val?

Des i ar gradece-mi o mia senhor,

por que o faç'; e, pois eu tod' est' ei,

o trobar nunca [o] leixarei,

poi-lo ben faç' e ei [i] gran sabor 
"Tirar do trovar um grande sabor" - é um derradeiro imiscuir-se na esfera de atitudes da nobreza para com a trova. O jogral declara que, da mesma forma que muitos fidalgos trovam por um prazer do espírito, o trovar é para ele muito mais do que uma profissão. Rejeição, portanto, daquela habitual demarcação dos trovadores-fidalgos segundo a qual a poesia deve ser para o jogral apenas uma profissão, um meio de subsistência, se possível na função de mero acompanhante dos trovadores nobres.

Conforme dizíamos, parece que, a certa altura, Lourenço teria ultrapassado os limites da impertinência possível dentro do paço trovadoresco português. Em uma tenção contra ele (CV 1032), o trovador-fidalgo Rodrigo Eanes parece insinuar que o jogral deixou de ser recebido na corte portuguesa:

- Lourenç', enas terras u eu andei,

non vi vilão tan mal departir

e vejo-te [de] trobares cousir

e loar-te; mais ua coisa sei

de tod' omen que entendudo for:

non averá en teu cantar sabor

nen cho colherán en casa del-Rei

À habitual acusação de "trovar mal", Lourenço responde com o autoelogio que tanto incomodava a fidalguia tradicional:

- Rodrigu' Eanes, u meu cantar for,

non acha[rá] rei nen emperador

que non o colha, - mui ben eu o sei.

Quanto à informação de que já não o queriam receber na corte portuguesa, pode ter algum fundamento. Primeiro porque, logo a seguir, já aparece na corte de Castela "tençoando" contra os fidalgos de lá. Depois, porque é desta época o decreto de D. Afonso III que, entre 1258 e 1261, reduziu para

3 Portugaliae Monumenta Historica. Leges et Consuetudines, 1 vol e 1 fasc. do vol II publ, Lisboa: Academia de Ciências, 1856-1868, p. 199, apud MATTOSO, José. Identificação de um País, Lisboa: Estampa, 1986, v. II, p. 60. três o número de jograis permanentes na corte portuguesa. ${ }^{3}$ Entrar e atuar no Paço era certamente a ambição de todo o jogral desta época. Afinal, a corte régia era um centro para onde todas as atenções se voltavam, e seus saraus palacianos desempenhavam no universo das ambições artísticas um papel comparável ao das grandes emissoras de televisão no mundo 
moderno. A partir desta "vitrine" que era o paço trovadoresco, um artista podia se tornar conhecido e conquistar um lugar entre seus pares, além de um reconhecimento da sociedade mais ampla que lhe poderia abrir outras oportunidades fora do ambiente cortesão.

A corte trovadoresca, diga-se de passagem, era mais um dos instrumentos com os quais o rei podia interferir no cotidiano de sua sociedade, nas suas expectativas, no controle de seu tempo e de seu lazer. Portanto um espaço de poder, que beneficiava também os indivíduos que circulavam em torno da figura régia. Colocado desta forma, não é de se estranhar que o jogral Lourenço, indignado com a interdição à sua atuação no Paço português, tenha desabafado suas queixas contra os validos de D. Afonso III. Um sirvantês que aparece no seu cancioneirinho, mas também no de Martim Moxa, é considerado pela romanista Carolina Michaëlis como uma tenção entre os dois jograis, onde estes se dispõem a criticar os privados portugueses. Teriam então se utilizado de uma forma não clássica de tenção, em que não aparece o nome de cada contendor no princípio de cada estrofe:

Vós, que soedes en corte morar, desses privados queria saber se lhes á privança muito durar: ca os non vejo dar nen despender, ante lhes vejo tomar e pedir; e o que lhes non quer dar ou servir non pode ren con el-Rei adubar.

Destes privados non sei novelar senon que lhes vejo mui gran poder e grandes rendas, casas guaanhar; e vejo as gentes muito emprovecer e, con proveza, da terra sair; e à el-Rei sabor de os ouvir, mais eu non sei que lhe van conselhar.

Sodes de cort' e non sabedes ren; ca mester faz a tod' omen que dé, pois à corte por livrar algo ven; ca, se dar non quer, por end' escass' é; pense de dar, non se trabalhe d' al; 
e, se non der, non pod' adubar al,

ca os privados queren que lhes den.

(Martin Moxa / Lourenço; CBN 888)

Seja uma tenção com a participação de Lourenço, ou então um sirvantês que o jogral passou a incluir em seu repertório, a verdade é que ele devia expressar com exatidão a indignação de Lourenço contra seus insucessos na corte portuguesa. Além disso, ele nos dá conta da trajetória que o jogral a partir daí tomou ("e vejo as gentes muito emprovecer / e, con proveza, da terra sair"; v. 11-12). De fato, em um segundo momento de sua carreira já o veremos na corte rival de Castela, o que confirma mais uma vez aquela hipótese de que as duas cortes trovadorescas funcionavam como os polos de um eixo em que circulavam os trovadores galego-portugueses. Tal como haviam feito os nobres exilados de Portugal, o jogral foi buscar na corte castelhana um novo espaço de expressão e de busca por prestígio pessoal.

Adota o mesmo estilo impertinente e persiste no propósito de continuar se inserindo no grande disputatio lírico que também ressoava em Castela. A corte de Afonso X não tinha a essa época qualquer restrição ao número de jograis (atitude de maior abertura que também seria mais tarde encampada por D. Dinis de Portugal). Por isso Lourenço pôde dar encaminhamento à sua atividade poética e satírica, e logo já estava "tençoando" contra o fidalgo português João Vasques, a esta altura também residente em Castela:

- Joan Vaásquez, moiro por saber de vós por que leixastes o trobar ou se foi el vós primeiro leixar, ca vedes o que ouço a todos dizer: ca o trobar acordou-s' en atal: qu' estava vosco en pecado mortal e leixa[r] vos [foi], por se non perder.

- Lourenço, tu vées por aprender de min, e eu non cho quero negar: eu trobo ben quanto quero trobar, pero non o quero sempre fazer; mais di-me ti, que trobas desigual, 
se te deitan poren de Portugal,

ou mataste omen ou roubaste aver?

- Joan Vaásquez, nunca roubei ren

nen matei omen, nen ar mereci

por que mi deitassen, mais vii aqui

por gaar algo; e, pois sei iguar-mi ben

con esse trobar vosso, mais estou

que se perdia con vosqu' e quitou-

se de vós; e non trobades poren.

(Lourenço e Joan Vaásquez; CV 1035)

Desafiado por Lourenço, o infanção português entrincheira-se na previsível posição demarcadora. Pretende insinuar, como sempre ocorre nestes casos, a sua superioridade natural em relação ao adversário não nobre ("Lourenço, tu vees por aprender / de min, e eu non cho quero negar", v. 8-9). Novamente vemos aqui, ainda na segunda estrofe, a crítica de um trovador-fidalgo ao trovar de Lourenço ("mais di-me de ti, que trobas desigual"). Desnecessário dizer que é a mesma crítica infundada que vem a reboque da repressão dos trovadores-fidalgos contra a atividade criadora dos jograis e segréis. Tanto mais se tratando de Lourenço, presença tão incômoda para os trovadores menos hábeis.

É hora então de dizer que não há nada de desigual no trovar de Lourenço, como podem atestar as suas próprias cantigas. Tampouco pode haver com sua música, já que o conhecimento musical do jogral é atestado por sua atividade anterior de organista da catedral de Santiago (LAPA, 1981, p. 145). Quanto à criatividade do jogral, é bastante evidente. Nesta tenção entre o jogral Lourenço e o trovador-fidalgo João Vasques, poderíamos mesmo esboçar a avaliação de que, se fosse possível estabelecer um vencedor do duelo lírico, este seria Lourenço. Afinal, à criativa declaração de Lourenço de que o trovar fugira de Vasques para não se perder, pois estava em pecado junto ao fidalgo ("moiro de saber de vós por que leixastes o trobar, ou se foi el vós primeiro leixar"), o infanção não consegue senão replicar com a grosseira pergunta sobre a procedência do jogral, se ele fora expulso de Portugal por roubo ou por homicídio ("se te deitan poren de Portugal, ou mataste omen ou roubaste aver?", v.13-14). 
Trata-se, em todo o caso, de um fragmento de discurso passível de ser examinado nos seus aspectos psicológicos. Escapa nos versos do fidalgo um "pânico íntimo", secreto temor diante dos novos grupos sociais que passam a roubar a cena da fidalguia nestes novos tempos medievais - lá fora, na guerra em que se projeta para além do desejável uma cavalaria-vilã e uma peonagem besteira; aqui, nos palcos trovadorescos do intrapaço, onde os poetas-cantores não aristocratas já se igualam no espaço composicional aos trovadores-fidalgos.

Quem Lourenço teria matado em Portugal, senão a própria nobreza trovadoresca - simbolicamente - provando com seus hábeis cantares ser tão bom na trova quanto qualquer nobre, ou ainda melhor? Que "haver" teria Lourenço roubado em Portugal senão o prestígio cultural, o reconhecimento dos pares mesmo que a contragosto? Precisamente por causa deste "roubo" e deste assassinato simbólico, que para a fidalguia trovadoresca já parecia ir além dos limites, Lourenço é expulso de seu paço natal. Antes que o peão alcance a "oitava casa" do tabuleiro social, conquistando o máximo nível trovadoresco e transmudando-se em peça de real valor, o meio aristocrata o alija da corte, empurrando-o para fora do jogo trovadoresco através da censura e do próprio mal-estar que a presença de Lourenço parece lhes causar. Mal-estar que migra em seguida para Castela, e que agora parece afetar o fidalgo João Vasques ao mesmo tempo em que escapa pelos atos-falhos poéticos, denunciadores de um inconsciente que teme o "talento não aristocrata" encarnado na figura do impertinente jogral.

Note-se também a alusão de João Vasques à situação econômica inferior do jogral, ou à sua dependência de donativos na rede trovadoresca (v.8-11). Aqui, o fidalgo encaminha a sua crítica por oposição ao modelo que pretende estabelecer em si mesmo. Ele próprio é o protótipo do trovador "diletante", que não depende da atividade poética para a sua própria subsistência. Assim, pode afirmar orgulhoso que "eu trobo ben quanto quero trobar, pero non o quero sempre fazer" (v.10-11). Lourenço, por sua vez, defende-se reconhecendo que de fato estava em Castela para "ganhar algo" ("mais vii aqui / por gaar algo"; v.17/18). Mas que, enfim, não reconhece nisto qualquer problema. A antiga polêmica sobre o que, afinal, legitima o trovar. 
A produção satírica do jogral Lourenço, sua trajetória no circuito ibérico, as resistências que teve enfrentar ao mesmo tempo em que ia se projetando no espaço trovadoresco, tudo isto nos leva a um quadro no qual a pluralidade se abre também para o jogral de condição social inferior, mas ao mesmo tempo em que os limites se impõem. Limites que, poderíamos dizer, são hegemonicamente conformados pelo confronto e combinação dos diversos interesses palacianos, aí incluídos não apenas o rei e todo o seu circuito centralizador como também a restante nobreza que frequenta a corte, inclusive a que se coloca criticamente perante o monarca. Dessa resultante de muitas forças sociais em permanente movimento, portanto uma resultante também em contínua transformação, é que parece se originar este "campo de força social" dentro do qual atua o jogral que frequenta o paço trovadoresco. Aqui, desafiando infanções e ricos-homens; ali, obrigando-se a ser mais comedido ou então a migrar para a corte vizinha.

Registro final deste confronto entre as duas pontas extremas da pluralidade social trovadoresca - o nobre poderoso e o humilde jogral - é a tenção entre o fidalgo Men Rodrigues Tenório e o jogral Juião Bolseiro:

- Juião, quero tigo fazer, se tu quiseres, ua entençon: e querrei-te, na primeira razon, ua punhada mui grande poer eno rostro, e chamar-te rapaz mui mao; e creo que assi faz boa entençon quena quer fazer.

- Meen Rodriguez, mui sen meu prazer

a farei vosc', assi Deus me perdon: ca vos averei de chamar cochon, pois que eu a punhada receber; des i trobar-vos-ei mui mal assaz, e atal entençon, se a vós praz, a farei vosco mui sen meu prazer.

- Juião, pois tigo começar fui, direi-t' ora o que farei: ua punhada grande te darei, 
des i querrei-te muitos couces dar na garganta, por te ferir peor, que nunca vilão aja sabor doutra tençon comego começar.

- Meen Rodriguez, querrei-m' en parar, se Deus me valha, como vos direi: coteife nojoso vos chamarei, pois que eu a punhada recadar; des i direi, pois so os couces for: 'Le[i]xade-m' ora, por Nostro Senhor', ca assi se sol meu padr' a en parar.

- Juião, pois que $t^{\prime}$ eu [for] filhar pelos cabelos e que $t^{\prime}$ arrastrar, que dos couces te pès eu creerei.

- Meen Rodríguez, se m' eu estropiar, ou se me fano, ou se $\mathrm{m}^{\prime}$ entortar, ai, trobador, já vos non travarei (Meen Rodríguez Tenoiro e Juião Bolseiro; CBN 403)

Mem Rodrigues Tenório pertencia a uma das mais ilustres famílias galegas e à melhor nobreza da Península. Quanto a Juião Bolseiro, era um jogral que também atuava com sua margem de atrevimento, embora muito menos que Lourenço, mas que aqui aparece curiosamente comedido diante das ameaças de Tenório.

De fato, estamos diante de uma tenção "proposta em termos de rara brutalidade" (LAPA, 1975, p. 447). Quase que toma a forma lírica de uma "briga de rua", não fosse que, à total agressividade de Tenório, Juião Bolseiro replica com certo comedimento. Enquanto o fidalgo principia por dizer que sua primeira razão é um murro no rosto (v. 4-5), Juião no máximo o responde com alguns insultos ("cochon", por exemplo, que é uma expressão pejorativa normalmente dirigida por aristocratas a vilãos). Talvez que, sem querer partir para o que poderia descambar para um confronto físico, ou então extrapolar a tensão trovadoresca apresentada liricamente, o jogral tenta responder com mais dignidade e astúcia poéti- 
ca. Apropria-se então das próprias palavras injuriosas que os nobres costumavam dirigir aos vilãos e procura voltá-las contra o fidalgo agressor, talvez a insinuar algo sobre quem se comporta como um verdadeiro "cochão" (v. 10), ou ainda um "coteife nojoso" (v. 24).

Tenório, por sua vez, continua ao longo de todas as estrofes a desfechar suas ameaças físicas, como por exemplo na terceira estrofe, onde afirma que "irá lhe dar muitos coices na garganta, para feri-lo tanto que desde então nenhum vilão mais se atreverá a entençoar com ele" (v. 18/21). É a demarcação social levada a seu extremo, com rara agressividade em uma tenção trovadoresca neste meio em que tudo parece se resolver liricamente. Significativo nos parece o contraste entre a agressividade do nobre e o relativo comedimento do jogral, pois nos mostra que os limites de um não são iguais aos limites do outro. Em todo o caso, o exemplo acima fica apenas como um registro extremo desta oposição entre dois representantes de segmentos sociais que se antagonizam através da sátira trovadoresca. Oposição que, na maior parte das vezes se concentra na disputa estritamente lírica, na desmoralização pelo riso, no rebaixamento pela palavra. $\mathrm{O}$ "combate corpo a corpo" assume em quase todos estes casos a forma de um "combate verso a verso", e se volta fundamentalmente para o campo da "violência simbólica". ${ }^{4}$ Aí se enquadram também as já estudadas interdições à palavra poética, com as quais todo um setor da nobreza ambiciona exercer sobre os segmentos não aristocráticos um "monopólio da força simbólica". Sem sucesso, pelo menos dentro dos limites do paço trovadoresco.

A tenção entre Tenório e Juião também faz ressoar o curioso contraponto entre dois tipos de "poder social". A "força física", seja o potencial de agressividade individual de um guerreiro como o poderio militar do grupo no qual ele se inscreve, sempre foi um fator importante na determinação do "poder social" da sociedade guerreira feudal. Com a emergência da cortesia, passam a competir com este fator preponderante outras oportunidades de poder social, inclusive acessíveis àqueles que não participam do monopólio de violência física, como os jograis que conseguiam se expressar

4 Conceito desenvolvido por Pierre Bourdieu e J. C. Passeron, 1990. na arena trovadoresca. A habilidade poética e satírica torna-se aí um instrumento de poder de primeira ordem, tão eficaz 
como outros que continuavam preponderantes fora do paço trovadoresco. Meios relativamente pacíficos, como a intriga e a diplomacia, também vão ganhando cada vez mais espaço na luta por "oportunidades de poder". ${ }^{5}$ Todas essas armas se entrechocam na arena da corte, livremente empunhadas pelos combatentes que competem pelo reconhecimento social.

O confronto entre a "força física" e a "força poética" é, outrossim, ressonância de colisões mais amplas que expressam as acomodações de um lento "processo civilizador" que vai transformando a sociedade europeia, na passagem da "idade do ferro" da nobreza guerreira para a "idade do mármore" da nobreza cortesã. A corte vai gradualmente se convertendo em um "edifício de mármore", composto por "homens que são muito duros, mas também muito polidos" (LA BRUYÈRE, 1922, p. 211). E é o combate entre a "dureza" e a "polidez", neste alvorecer de uma nova civilidade, que parece reger o entrechoque entre as figuras do "guerreiro" e do "cortesão", por vezes se debatendo no interior de um mesmo indivíduo.

Na cantiga que ora analisamos, o mais curioso é que, no confronto entre a brutalidade e a civilidade, é o jogral que empunha a segunda bandeira, quando a tendência histórica confirmaria a apropriação da "polidez" como um distintivo social da classe aristocrática. No próprio século XIII, numerosos "manuais de cortesia" começam a invadir a literatura cortesã. Um exemplo notável é o Hofzucht, do minnesänger Tannhäuser - verdadeiro manual de "maneiras corteses". Os novos códigos de comportamento, apregoando o autocontrole e a polidez, são os mais recentes símbolos de distinção social da nobreza de corte. "O comportamento nobre, cortês, é constantemente confrontado com as 'maneiras rudes', a conduta do camponês" (ELIAS, 1990, p. 77). Desta forma, aos olhos de uma nobreza que começa a se distinguir pela cortesia, e do código de comportamento que está surgindo nas grandes cortes feudais, a atitude mais rude do fidalgo Tenoiro é que seria passível de crítica. Talvez que, nas "cortes de amor", mediadas pela presença das mulheres de sociedade e temperadas por um refinamento mais estudado, a atitude do trovador-fidalgo fosse outra. Mas as "cortes satíricas" são o locus da espontaneidade. Além do que,

5 Expressão introduzida por Norbert Elias (1990. v. 2. p. 18). tal como fizemos notar, ainda estamos aqui em um tempo de colisões, de entrelaçamento de uma sociedade e de outra, de 
6 Vale a pena lembrar que, consoante a moderna teoria do drama, certos diálogos são também uma forma de ação: "a ação projetada pela fala pode ser retrospectiva ou potencial, ou pode ser concomitante. Mas o único teste para a eficiência do que está sendo dito está na sua concretude, no impacto físico, na sua qualidade de tensão" (CLARK, 1959. p. 543). "querela entre o ferro e o mármore", antes que o segundo se torne a substância definitiva na constituição das almas da corte.

Para o caso da tenção entre Tenório e Bolseiro, devemos ainda assinalar a possibilidade de que nela predominasse um caráter lúdico e quase teatral, abrindo-se inclusive a possibilidade de se tratar de uma tenção mais ou menos ensaiada. Mas isso não invalida as questões da violência simbólica encaminhada pela fidalguia contra a vilania trovadoresca, que apareceriam sub-repticiamente.

Ainda que Juião Bolseiro tenha sido pago para representar um papel, e que haja uma violência ensaiada, o entrechoque entre os papéis da fidalguia e da vilania trovadoresca está em cena. O mesmo se pode dizer do entrechoque entre a rudeza do fidalgo Tenório e a polidez, que também tem lugar nos palcos trovadorescos.

Em reforço a esta observação, e antecipando a hipótese de que a arena trovadoresca se inscreve em uma "dramaturgia política" instituída pela própria estratégia cultural dos monarcas centralizadores, destacamos o caráter profundamente dramático do diálogo que opõe Tenório e Bolseiro. O diálogo do escárnio é aqui uma ação, índice de colisões sociais que encontram sua forma final na oposição eminentemente violenta entre duas vontades, a do fidalgo Tenório e a do jogral Bolseiro. O objetivo do jogral em ascender sócio-trovadorescamente e a interdição que o fidalgo opõe a este movimento, eis aí o pequeno drama que se encontra oculto nesta singular cantiga, seja ela espontânea ou ensaiada. A tenção - o diálogo - torna-se aqui um sutil teatro para a colisão de paixões sociais mais profundas. ${ }^{6}$

Em que pese a resistência que os poetas-cantores não aristocratas sempre tiveram que enfrentar, alguns jograis chegaram mesmo a conquistar uma liberdade efetiva para criticar a hierarquização social do seu tempo. Como o célebre Martim Moxa, respeitado até mesmo pelos aristocratas mais demarcadores. A celebridade e popularidade dos cantares de Martim Moxa é atestada até mesmo nas cantigas de outros, que eventualmente o citaram nos seus próprios versos (por exemplo a CV 1062, do escudeiro João da Gaia, ou a CV 470 de Afonso Gomez).

Moxa foi um dos trovadores mais críticos de seu tempo. Sua poesia satírica, porém, não descamba para os ataques 
meramente pessoais (contra os quais ele se bate na CBN 896). Sua longa carreira, que devido à longevidade do jogral acaba por coincidir com todo o período áureo do trovadorismo, está repleta de versos contra as maldades do mundo em que vivia, inclusive no sentido social mais amplo. Por isso seu tom é sempre apocalíptico, carregado de queixas que não se limitam a reivindicar um melhor lugar social para si mesmo. Ao contrário, bate-se contra esse mundo às avessas, "ca vejo boos cada dia decer / e vejo maos sobr' eles poder" (CBN 889). "Em um mundo como esse, a morte seria até preferível". Logo ele, que teve uma vida tão longa, a ponto de gerar um escárnio pelo qual o acusam de assegurar uma sobrevida mediante um elixir de ervas mágicas (CBN 886). Em todo o caso, sua extensa vida poética foi dedicada à contestação, onde se batia contra as injustiças do mundo sem poupar nem Igreja nem fidalgo. Oportuno lembrar aqui a cantiga em que Moxa narra um curioso sonho que teve:

Mentr'ali foi, tal sonho' ôuvi a sonhar: muitas vezes, eno sonho. [a]quem,

vi a bubela a cerzeta filhar:

e a bubela, a[a] crista que ten

a cerzeta, quen ouver'a dizer

en com' a pôde a bubela prender!

Este sonho, qué-no pode soltar?

(Martin Moxa, CV 915, última estrofe)

Neste sonho, descrito na última estrofe de um sirvantês em que protesta contra um senhor arrogante, o jogral nos fala de uma pequenina bubela ${ }^{7}$ que teria dominado facilmente uma cerzeta, pássaro de muito maior envergadura. O jogo de imagens evocado pelo poeta é extraordinariamente rico em ambivalências. Em um primeiro momento, a cerzeta parece pretender dominar a bubela pela crista, agarrando-se a ela com o bico, mas na sequência poética é a própria cerzeta que aparece dominada pelo pássaro menor. Desta forma, a imagem propõe uma enigmática inversão: a cerzeta almejava vencer a bubela

7 Ave de pequeno tamanho, hoje conhecida como "poupa". prendendo-a pela crista, mas a crista é que parece dominá-la e termina por impossibilitar suas reações e movimentos. Na passagem da imagem visual à imagem poética e à proposta 
8 Sobre o uso de alegorias ver o hábil manejo de "personificações de virtudes" na CV 502, onde Moxa investe contra o mundo decadente ao qual se opõe. A utilização recorrente da "personificação alegórica" na obra de Moxa lembra por vezes o trovador provençal Marcabru, outro virulento poeta-cantor de discurso apocalíptico sobre o "mundo às avessas" e a imoralidade da sociedade que o constituía. do enigma, com efeito, a poupa já aparece vitoriosa. Desta forma, um sentido dominante no sonho é a vitória do pássaro pequeno sobre o maior, contrariando as expectativas naturais.

Entramos aqui no universo dos símbolos e alegorias, recursos estilísticos que são característicos de Martim Moxa e que o convertem em um caso singular do trovadorismo galego-português. ${ }^{8}$ Mas também entramos no mundo das imagens, carregadas de intencionalidades premeditadas e de motivações inconscientes. Para além disso, com esta enigmática cantiga invadimos o mundo dos sonhos, com todas as suas implicações psicanalíticas.

O que nos oferece o jogral com a sua inusitada fantasia alegórica? Um sonho, ou um enigma? Um ou outro parece nos conduzir à descoberta das mesmas motivações internas. A considerar a teoria de Freud (1967), o sonho aponta via de regra para a realização de um desejo. Qual o desejo oculto de Martim Moxa, devemos buscá-lo na perscrutação das zonas de enunciação de seu discurso. Esta perscrutação deve avançar para além do dito, por mais sedutora que seja a sua enunciação poética e a sua sutileza metafórica, e desconstruí-lo para atingir o "vazio do discurso". Este vazio que, contudo, "não é uma realidade una. Dentro dele vislumbramos a formação de duas zonas, a que chamaremos as zonas do entredito e do interdito" (LIMA, 1974, p. 18).

Um primeiro sentido do poema refere-se ao senhor poderoso e arrogante que, destarte, é dominado pela lisonja dos bajuladores que o cercam, simbolizados aqui pela pequena ave que o domina pela mediação da crista. A crista, símbolo da bajulação e arquétipo de uma dissimulação ornamental, remete também à vaidade e à arrogância. Quem tem a crista: a bubela que a exibe em forma de penacho colorido, ou a cerzeta arrogante e vaidosa que se deixa dominar por ela? A imagem da crista é aqui tremendamente ambígua; torna-se especialmente significativa, sobretudo em referência às duas primeiras estrofes que aqui não foram reproduzidas. Nelas o poeta descreve um ambiente de lisonja ou bajulação, onde só é possível prosperar enaltecendo servilmente as mais absurdas aleivosias do senhor ("nen pod" om'i de senhor gaar ren / se non loar quanto lhi vir fazer, / e lousin[h]ar e ren non lhi dizer, / pero lhi veja o sal semear"). 
A metáfora do senhor que é facilmente dominado pela crista, pela crista do "outro" que não consegue mais soltar - o que vale dizer, pela lisonja que lhe aprisiona a vaidade - aponta aqui para o enunciado mais óbvio, para o dito, esta primeira zona de enunciação do discurso. “O dito é a palavra do falante. Esta deixa uma sombra, a sombra do implícito, voluntário ou involuntário. Se desconstituímos o corpo do dito e a sua sombra, aparece a primeira camada de uma nova dimensão, o entredito." (LIMA, 1974, p. 18). Para além disto, o senhor que termina dominado por aquele a quem pretendia antes sujeitar remete a uma dramatização inconsciente da "dialética do senhor e do escravo" $^{\prime \prime}$ - do senhor que se torna um escravo do escravo e dele já não se pode libertar. O que já é, em todo o caso, um segundo sentido que se acopla ao primeiro. Prossigamos, de qualquer forma, na busca do mais secreto desejo de Martim Moxa.

Obviamente que, senhor arrogante e bajuladores que se beneficiam das suas arbitrariedades, eis aí dois complementares que são criticados por Moxa em diversos de seus poemas. Não é esta a cena que representa o mundo dos desejos do jogral, seguramente. Esta primeira interpretação possível não deve portanto nos impedir de ir mais além, para "a outra cena", para a apreciação de uma zona de enunciação que expressa, esta sim, o secreto desejo de Martim Moxa - este profeta apocalíptico que sonhava com um mundo sem senhores e injustiças sociais. O dito e sua sombra - a metáfora e seu significado implícito abrem caminho, ou bloqueiam o caminho, de uma silenciosa zona de enunciação, mais visceral e mais profunda. Atingimos neste momento a zona do entredito. Aqui a bubela assume literalmente o sentido do pequeno, da avezinha que domina a arrogante cerzeta em inesperada inversão de forças e valores.

O secreto desejo de ver invertida uma cosmogonia social que se coloca para o poeta como o território da injustiça e da iniquidade, eis aqui o entredito do sonho. $\mathrm{O}$ que seria o seu interdito senão a decidida recusa de uma cadeia de dependências feudo-vassálicas e senhoriais que permite a injustiça, a bajulação, a arrogante cerzeta e a submissa bubela aduladora, esta que encobre a verdadeira bubela, a pequenina ave que guarda um potencial de subversão e que está pronta a destruir

9 Expressão que tomamos de empréstimo a HEGEL (1939). através da crista - em algum ponto do imaginário - a mesma cadeia social que a oprime? 
A bubela de Martim Moxa é portanto ambígua, remetendo a uma dupla codificação. De um lado, a codificação cotidiana da mesquinhez dos bajuladores e dos senhores lisonjeáveis, exposta pelo sentido metafórico que aparece em primeiro plano. De outro, a codificação de uma cosmogonia social que finalmente se inverte, pelo menos em sonho, e ameaça resgatar todas as injustiças sociais. A crista transmuta-se de símbolo da bajulação e da mesquinhez em símbolo da grandeza e da força. Mediante ela a bubela, o pequeno laboratore, pode encaminhar a sua vitória final. A "outra cena" é desta forma a rebelião, a revolta que se torna possível à bubela sem o concurso do sobrenatural ou da intervenção fantástica, ainda que seja evocada uma imagem inusitada, mas em todo o caso possível. A eficácia de tal imagem reside, aliás, na possibilidade de ela ser pensada como realizável, ainda que seja uma cena inédita.

É difícil ler o poema de Martim Moxa sem evocar de imediato, como matéria impressional, a cena descrita na última estrofe. Menos fácil, talvez para a segurança e comodidade sociais do próprio poeta, é perceber que nesta imagem - a pequenina bubela que vence a cerzeta - concorrem as duas intencionalidades da imagem, atrás descritas. Uma ou outra, a imagem da bubela não é "uma vaga fosforescência, um rastro deixado na consciência [do poeta] pela percepção [de um pequeno pássaro]". ${ }^{10}$ É uma "forma de consciência organizada" que se relaciona, à sua maneira, não apenas ao ser "bubela" como também a um conjunto de questões que afligem o trovador. Imagem e signo, a bubela de Martim Moxa é uma das maneiras possíveis de visitar a pequenez real do humilde trabalhador, a pretexto de visitar a pequenez real do pássaro. E deixar que falem ao mesmo tempo, como só a poesia e a imagem poderiam permitir, uma atitude e outra abertas a este mesmo trabalhador. A adulação e a revolta, o vencer pela pequenez ou o vencer apesar da pequenez, eis aí o secreto combate que se deflagra nos entreditos e entreversos.

A rebelião que se entrincheira nos entreditos do discur-

${ }^{10}$ Aproveitamos as $1 \mathrm{i}$ nhas mestras de um texto em que Sartre discute, mediante um exemplo simples, a questão da "imagem" e da "intencionalidade da imagem" (SARTRE, 1973. p. 106). so poético de Martim Moxa torna-se ainda mais ressonante, sobretudo se invocamos a já estudada importância adquirida pelo sonho dentro do imaginário cristão ocidental (LE GOFF, 1994). O sonho como instrumento de revelação, de anúncio de acontecimentos futuros, mostra-se presente em inúmeras 
passagens do Antigo Testamento, e é deste universo bíblico que o "sonho-revelação" é importado para as crônicas medievais - estas elegendo como receptores oníricos privilegiados os santos e bispos, mas também os reis e os nobres. Há um status social que é observado pela cronística tradicional para o privilégio da recepção do sonho.

Mas quem poderia receber um sonho de rebelião, de anúncio do insólito acontecimento de inversão da hierarquia feudal - insólito mas perfeitamente realizável dentro dos limites físicos, ao considerar a escolha inconsciente de uma simbologia sem o concurso do maravilhoso - quem poderia receber este sonho, esta "revelação" de uma revolta, senão o próprio Martim Moxa, poeta independente e saído do povo?

No espaço mágico da poética trovadoresca, sonhar com a revolta é promover a própria revolta. “Um grande verso pode ter grande influência sobre a alma de uma língua. Faz despertar as imagens apagadas. E ao mesmo tempo sanciona a "imprevisibilidade da palavra" (BACHELARD, 1974, p. 349). O poema de Martim Moxa sanciona, talvez, a imprevisibilidade da própria imagem. Traz inesperadamente a bubela para o centro da cena e anuncia que, talvez em um tempo futuro, aquilo mesmo que a bubela representa virá ocupar a sua parte no palco. Esta imagem que se encontra apagada, em forma de vaga esperança esvoaçante sobre o imaginário das massas laboratores, e em forma de pálido receio entranhado no "não dito" nobiliárquico - esta imagem adquire com o verso do poeta-cantor contornos surpreendentes. O oprimido que antes parecia destinado a ser dominado pelo bico do opressor inverte todas as expectativas. O pequeno pássaro finalmente venceu, o mundo é reordenado consoante uma nova lógica que subverte o enlaçamento feudal.

A percepção de que é o próprio enlaçamento feudal que o poeta intimamente rejeita pode ser reforçada se evocarmos mais uma vez o princípio psicanalítico da denegação. Frequentemente, uma imagem interdita sobe ao consciente sob a forma de uma aparente negativa, mas que na verdade corresponde ao aspecto da realidade que o inconsciente pretende afirmar. Mas afirma-o (nega-o) mediante um intermesclamento de negação, supressão, conservação e suspensão. ${ }^{11}$ 
A imagem trazida à tona pelo sonho de Martim Moxa é rica em potencialidades de afirmar e negar ao mesmo tempo. É uma imagem que, no primeiro extrato de sentido, representa o estabelecimento de compromissos feudais: a bubela e a cerzeta acham-se aprisionadas uma à outra pela mediação da crista. Encontra-se representada, neste caso, a conservação de uma relação que o poeta rejeita na construção de seu mundo ideal, tal como fica patente em diversos de seus outros poemas. Mas é uma imagem também de insurreição, de superação do sistema, uma vez que o resultado final da cena é a vitória da bubela e a inversão de expectativas.

Avançar para novas zonas de enunciação do poema seria penetrar na enigmática personalidade de Martim Moxa. Talvez descobríssemos medos, para além de desejos. No inconsciente, medos e desejos eventualmente se confundem. Dar espaço poético à bubela aduladora, enquanto sonho ou enigma, pode representar o medo inconsciente de se tornar uma, de ser um dia captado pela teia de interdependências e ser devorado pelas aranhas da necessidade, ele - clérigo errante tão cioso de sua liberdade. Mas isto já nos levaria para os limites do não analisável. Freud observou certa vez que "todo sonho tem pelo menos um ponto onde é insondável, como um umbigo através do qual é ligado ao desconhecido" (apud CASTORIADIS, 1986, p. 321). Há sempre este "novelo de pensamento do sonho que não deixa desenredar" (ibidem, p. 322).

Este é talvez o "umbigo" do sonho de Martim Moxa - a parte onde ele se conecta ao desconhecido. Mas tal zona de enunciação, mesmo que fosse possível interpelá-la, conduziria para além do que interessa neste momento: o mais secreto desejo coletivo, adormecido no inconsciente da multidão de miseráveis gerada naqueles tempos difíceis, e que, sem o saber, encontra voz neste poeta apocalíptico que apresenta sonhos e propõe enigmas.

11 Hegel (1939) utiliza a expressão "Aufhebung", que é também empregada por Freud, visando expressar com o mesmo significante a negação, a supressão, a conservação e a suspensão. Trata-se de uma palavra eminentemente dialética.

Martim Moxa quis dar ao seu poema a forma de um enigma que pede muitas respostas. É assim que, consciente dos múltiplos sentidos de seu poema ("este sonho, qué-no pode soltar?"), o poeta parece jogar com a alegoria de que os grandes poderiam um dia ser dominados pelos pequenos. Fantasia lírica, alguém poderia acrescentar, de um poeta que adquirira publicamente o direito de sonhar... 


\section{REFERÊNCIAS}

BACHELARD, Gaston. A Poética do Espaço. In: Os

Pensadores v.XXXVIII. São Paulo: Abril Cultural, 1974.

BOURDIEU, Pierre; PASSERON, J. C. La reproduction: Eléments pour une théorie du système d' enseignement. Paris: Minuit, 1990.

CASTORIADIS, C. A Instituição Imaginária da Sociedade. Tradução por Guy Reynaud. 2.ed., Rio: Paz e Terra, [1975] 1986. 418p.

CLARK, H. Barrett. European theories of drama. Nova York: Crown Publishers, 1959.

LIMA, Luiz Costa. Poética da Denotação. In: A metamorfose do silêncio. Rio de Janeiro: Eldorado, 1974.

ELIAS, Norbert. O Processo Civilizador. Rio de Janeiro: Jorge Zahar, 1990.

FREUD, Sigmund. The Interpretation of dreams. Londres: George Allen and Unwin, 1967.

HEGEL, Friedrich. Le phénoménologie de l'espirit. Paris: Montaigne, 1939.

LA BRUYÈRE. De la cour. In: . Ouvres. Paris: Hachette, 1922, v. II.

LAPA, Manuel Rodrigues. Lições de Literatura Portuguesa. 10. ed. Coimbra: Coimbra Ed.1981. Cantigas de Escárnio e de Mal Dizer. Lisboa: Galáxia, 1975.

LE GOFF, J. O Cristianismo e os Sonhos. In: . $\mathrm{O}$ Imaginário Medieval. Lisboa: Estampa, 1994.

LIMA, Luiz Costa. Poética da Denotação. In: A metamorfose do silêncio: análise do discurso literário. Rio de Janeiro: Eldorado, 1974.

MATTOSO, José. Identificação de um país: ensaio sobre as origens de Portugal, 1096-1325. Lisboa: Estampa, 1986, 2 vol.

SARTRE, Jean-Paul. A Imaginação. In: Os pensadores, v. XLV. São Paulo: Abril Cultural, 1973. 


\title{
FONTES
}

Cancioneiro da Ajuda. Edição de Carolina Michaëlis de Vasconcelos. Halle: 1904. 2 v.

Cancioneiro da Biblioteca Nacional Elza Paxeco Machado e José Pedro Machado (org.). Lisboa: Ocidente, 1949-1964.

Cancioneiro Portuguez da Vaticana. Edição de Teófilo Braga. Lisboa: 1878.

Documentos Medievais Portugueses. Documentos régios, v. I. tomo I e II. Lisboa: Academia Portuguesa de História, 1958-1961. Documento 202.

Livro de Linhagens do Conde D. Pedro. Edição de José Mattoso. “Nova Série" dos Portugaliae Monumenta Historica. Lisboa: A.C.L., 1980.

Livros Velhos de Linhagens. Edição de José Mattoso e Joseph Piel. "Nova Série" 2 Portugaliae Monumenta Historica. Lisboa: Academia de Ciências, 1980.

Portugaliae Monumenta Historica. Leges et Consuetudines, 1 vol e 1 fasc. do vol II publ, Lisboa: Academia de Ciências, 1856-1868.

\begin{abstract}
"Cheeky Minstrel" - The performance of low social class poets in the Iberian medieval troubadourism (XIII and XIV centuries)

The subject of this article is to discuss the social tensions in the Iberian medieval societies from the XIII and XIV centuries, examining most specifically the troubadours practice and poetry of this period through the chants of the minstrels from the troubadour's movement of Portugal and Castela in the second half of the XIII century. The aims is to examine how the poets of low social extraction, from different sections of the population, enter an area also frequented by the nobility and the King himself, especially in the social and cultural space of the Palace.
\end{abstract}

Key-words: Iberian medieval troubadours; socials tensions, minstrel. 